\title{
But what have you done for me lately? Commercial Publishing, Scholarly Communication, and Open-Access
}

\author{
John P. Conley \\ and \\ Myrna Wooders \\ Department of Economics \\ Vanderbilt University
}

\begin{abstract}
We discuss our experience in both commercial and open-access publishing. We argue that, in the papyrocentric (paper-centered) era before 1990, commercial publishers served a useful and necessary purpose. In the electronic era, post 2000, the academy has very little to gain from commercial publishers, who may actually impede rather than facilitate scholarly communication. We consider the costs of running an open-access journal and argue that they are considerably less than is commonly supposed. We describe the role of workflow and content-management software systems and how they can facilitate not only open-access journals, but also working-paper series, conference organization, scholarly societies, and other forms of scholarly communication.
\end{abstract}




\section{Introduction}

In the economics profession, there is a growing dissatisfaction with the closed-access model of scholarly communication. Recent increases in subscription prices charged to libraries especially have excited much concern. Bergstrom (2001), for example, argues that we should not voluntarily give our time to edit and review content that is destined to be published in expensive closed-access commercial journals. Boldrin and Levine (2008) argue that copyright and intellectual property rights in general are largely counterproductive and ought to be severely restricted.

Over the years, we have been involved in the founding of two journals, a scholarly society, the organization of numerous conferences, and the production of two software systems that support scholarly communication. The purpose of this article is to describe our experiences and what they suggest for the future of scholarly communication and, in particular, for the academy's relationship to commercial publishers.

We believe that before 1990, commercial publishers were a necessary part of the landscape of scholarly communication. They had specialized skills that could not readily be reproduced in the academy. This situation was largely due to the papyrocentric ${ }^{l}$ (papercentered) model of scholarly communication. However, by the year 2000, communication had shifted to the Internet and email. The 1990's were a decade of growth and transformation between the papyrocentric and electronic era of scholarly communication, and the academy is only now sorting out the implications of this transformation. The academy is moving to a completely new technological and economic publishing environment but, for reasons we will discuss below, this movement is slow.

\section{The Journal of Public Economic Theory and Commercial Publishing}

In the 1990's and before, the Journal of Public Economics (JPubE) was the dominant research outlet in its area of economics. JPubE was and is a fine journal that has made significant contributions to both research and policy. However, many people felt that it was focused on empirical research, especially on policy issues primarily of interest in the United States. While there was quite a bit of theoretical work being written in public economics, it tended to be published in a wide array of pure theory journals. As a result, there was no focal journal for the community of scholars doing work in public economic theory. As a consequence, these researchers tended to be absorbed into the peripheries of other research communities. In addition, the conversation between empirical/applied and

1 Stevan Harnad (1994) is generally credited with the invention of this term. 
theoretical public economists appeared to be limited. This state of affairs benefited neither set of scholars, nor the field of public economics in general.

Speculating about the impediments to research in public economic theory, however, has, by itself, limited value. If there really was an intellectual need for a new journal, it seemed sensible to do something about it. Thus, in 1996 we decided to found the Journal of Public Economic Theory (JPET). We began by putting together a proposal and asking people to join the editorial board. We were very gratified to discover how willing well-known economists were to voluntarily give their time and reputations to support the project.

After the core of the board was in place, we circulated our proposal to six major publishers. Within two months, we had four offers to publish, one refusal, and one request for more time to put the proposal through channels. We accepted Blackwell's offer because, at the time, it was a privately held company and seemed to be more interested in research and scholarly communications than its competitors. Blackwell has since been acquired by Wiley.

To support and promote JPET, we founded the Association for Public Economic Theory (APET). APET has now held nine conferences in places ranging from Tuscaloosa and Nashville, to Paris, Hanoi, and Beijing. Typically, about 200 to 300 researchers attend these events, and we expect somewhere close to 400 researchers at PET 09 Galway this June. More recently, APET has also sponsored small workshops with 20 to 40 people on specialized topics leading to special issues of the journal. More details are available at www.apet.org.

APET has played a very significant role in the development of JPET. Not only has it increased the visibility of the journal, but it has also brought together like-minded scholars to talk about theoretical public economics. We have particularity tried to include young scholars and to extend APET's reach outside the US.

The journal seems to have done well. Our first year, we had 60 submissions and published about 400 pages in four issues. This year, we are on track to receive about 300 submissions and publish about 1000 pages in six issues. Our overall acceptance rate is about $15-20 \%$. We were also accepted into the Social Science Citation Index in 2008. Our new electronic submission interface can be seen at www.jpet.net.

In 1996, when our idea of a new journal with a focus on public economic theory was conceived, we did not seriously consider open-access nor the possibility of a journal without a commercial publisher. It seemed to us that publishers were a necessary part of the process. They bore significant and unavoidable costs of facilitating scholarly communication, specifically:

- Typesetting: While some scholars could produce neat, finished papers with nicely formatted equations and well-executed pictures and graphs (which were often handdrawn), many scholars were less able in this regard. Even for those who could 
produce such manuscripts, there were many different incompatible systems and formats (TeX, LaTeX, Word, etc) in use. It may be hard to remember, but Acrobat 1.0 was first offered for Macs in 1993 and was not distributed as a free reader until almost 1995. By 1996, PDF technology was still new and not widely used. All in all, typesetting was a specialized and expensive process, but one which was necessary.

- Distribution: Even with a finished manuscript in hand, a scholar was faced with significant costs of distribution. Suppose you wanted to send your recent working paper to 200 people in the field. Perhaps it would cost $\$ 300$ to reproduce these copies of a 30 page manuscript and then another $\$ 400$ to mail (more if you sent papers overseas). You would also have to package and label each envelope, which cost time and effort. Even then, you would probably not know about young people just entering the profession who would be interested in seeing your manuscript, and of course, in any event, the mailing might result in only a few papers actually being read by the recipients. No central index would exist, and the burden of filing these papers would also be borne by the recipient. One can readily see why it was much more efficient to bind papers together into a journal and send them to libraries that would catalog and archive the contents. Thus, publishers simply had a strong comparative advantage in the distribution of new knowledge in the papyrocentric era.

- Advertising, subscription service, and production: Even if a scholar or society wanted to run its own journal, in the papyrocentric era, supporting the operations required all of the activities of commercial publishers. The journal had to be physically produced and then sent out to all of its subscribers. This is a costly, technically involved, and time-consuming process. To get subscribers, advertising, especially to a network of libraries, was required. Again, as scholars, we typically do not have the expertise, knowledge, or time to do this very easily. Thus, when paper journals were the best way to distribute new research, it is clear that commercial publishers were best equipped to undertake the task.

When we were getting JPET started, Ted Bergstrom suggested that we not involve a commercial publisher. At the time, we thought this as a bit idealistic, even quixotic. In addition to the concerns above, there was the fact that having the backing of a well-known press willing to spend money on a project would be perceived as a signal of the quality and staying power of the Journal. Whether this was a good decision in 1996, an interim period between the papyrocentric and electronic eras, is debatable. The enabling technologies were still new and not universally deployed. In retrospect, however, we have to concede that Professor Bergstrom may well have been correct in his recommendation. JPET may have done better to jump on the leading edge of this change. 
At this point in 2008 , well into the electronic era, except for the signaling value of spending money, we have come to the view that commercial publishers as they currently operate, whether papyrocentric or electronic, do more to hinder than facilitate the process of scholarly communication. This hindrance is due to a variety of changes in publishing technology.

First, word processing programs have become increasingly sophisticated, and almost all economists are able to produce their own very high quality manuscripts. Complimentary to this fact is that, by 2000, the PDF format was widely used and allowed a common way to transfer files independent of the software platform on which they were created. While there have been some compatibility problems (PDFs not being as portable as one might hope, it turns out), PDFs and advances in word processing make the typesetting services that publishers supply at best a luxury and do little materially to facilitate scholarly communication. There may be a minor advantage in having all papers formatted similarly but this is largely an aesthetic one. Typesetters, in general, do not have much expertise in the subjects they handle and so do not have much ability to add value in terms of improving mathematical or technical presentation. Indeed, in our experience, there are many cases in which typesetters detract from the article and offer unnecessary and even incorrect "improvements." Thus, publishers no longer have any advantage in this respect. Moreover, there are on-line professional editing services (albeit of varying quality).

Second, electronic distribution channels are now widely available and open to all. Before 1990, email was relatively new as a mass phenomenon. It was only in 1991 that AOL was first released, and this was only for a DOS environment. It took until 1993 for a Windows 3.0 version to be released. In the same spirit, the original Mosaic Browser was released in 1993 and Netscape only in 1994. Thus, in 1996, these were very new technologies. By 2000 , it was relatively easy to make manuscripts available online. One could count on most of one's professional colleagues to have access to email. Electronic archives of working papers such as $\operatorname{RePEc}^{2}$ (repec.org) became available. These archives indexed papers and made them freely available to all. In 2008, paper journals are essentially an anachronism, and their current existence is the result of hysteresis. Few people go to libraries anymore to get hard copies of journals. For many (especially younger) researchers, it may be that, if something does not exist online, it may as well not exist at all.

The question of the current value of advertising, subscription service, and production services is an interesting one that deserves more attention. Commercial publishers spend a great deal of money typesetting, producing, and sending out hard copies of journals. On the positive side, all this effort and expense can be viewed as a way to signal quality by "burning money." It is still meaningful that a journal exhibit a physical version. Of course, this state is a bit strange, because in effect, almost all journals are now available

2 RePEc was created in 1997 and is run many volunteers. One of the services run by RePEc is the working paper archive, WoPEc, which was created in 1993 by Thomas Krichel. 
electronically. It seems that very few people value a paper copy, but the fact of its existence may still give a kind of reassurance.

To make investment in a journal profitable for commercial publishers, they must do two things. First, careful effort must be taken to get libraries and others to subscribe. For this reason, publishers spend money on advertisement and promotions, pay for marketing departments, and so on. Second, careful effort must be made to see that only those who have subscribed have access to published content. In the papyrocentric era, this restriction only required mailing a copy of the journal to each library that subscribed. Now it involves complicated bundled agreements and sales to consortia in which access to specific publications is given to certain people who request content from designated IP addresses or through certain gateways. ${ }^{3}$

Putting this information together, the major contribution made by commercial publishers in the electronic era is in providing typesetting services (sometimes of dubious value), printing and distributing paper copies of journals that few really want, and negotiating and policing complicated access arrangements that limit the distribution of research. None of these activities support the mission of scholarly communication. Indeed, they mostly impede it. In a real sense, publishers have become the snake that eats its own tail. They produce revenue almost solely for the purpose of having enough income to fund the apparatus that allows them to collect revenue.

With new technologies, the only really significant costs remaining are producing research, certifying its correctness and value, and establishing the reputation of a particular research outlet.

The burden of research production has always fallen on the academy and its direct supporters (granting agencies, for example). Publishers never have-and never will-aid in this effort except when the publishers are non-profit or have a non-profit objective. Certification also always has been the business of the academy. It is academics (and some government and industry researchers) who edit and review manuscripts. One might argue that editorial salaries paid by publishers and stipends paid to referees by some journals play a role in getting quality certification. There is very little evidence to support this. The editorial salaries paid are generally small and by no means in proportion with time spent by editors on their duties. Many editors are not paid at all and associate editors almost always work for free. Neither does there seem to be a pattern in which higher quality journals pay for referees for reports more often than lower quality ones. To the extent that this is not true, these two small costs could easily be paid by submission fees. Of course, editors edit largely because they believe in the intellectual mission of the journal and expect to be paid indirectly by the satisfaction they experience by aiding the research of others, by furthering

3 One report says that Elsevier spent $\$ 30,000,000$ on such a workflow and content management system in 2000 (see Willinsky 2005). 
quality research, and by any prestige that their position offers. Referees have similar professional and intellectual motivations. Our experience at JPET is that highly regarded members of the profession are very willing to donate their time and lend their reputations if they believe in a journal's intellectual mission.

One rather odd legacy from the papyrocentric era is long delays in the publication of accepted papers. Backlogs of more than a year are not uncommon. Some of these are a result of the overhead of typesetting and handling of final drafts of accepted content. Most of these delays, however, result from a desire on the part of commercial publishers to produce a fixed number of pages of content per year. This is driven by the costs of producing and mailing physical copies of a journal, and also by the fact that the subscription prices charged to libraries are closely tied to the number of pages published in a given volume of a journal. Thus, while these publication delays are not related to whether or not a journal is open access per se (a commercial publisher certainly could officially publish all content immediately if it chose to), it does seem to be correlated to the commercial business model. ${ }^{4}$ As long as publishers set limits on how many pages a journal publishes per year, we will continue to see these delays which, of course, impede scholarly communication.

Finally, at one time, having a journal published by a leading academic press might have carried signal value. At the least, it showed that the firm was willing to commit resources and provide a kind of continuity guarantee. With publishers merging and the new "Big Deal" negotiations, ${ }^{5}$ however, this signal is becoming increasingly muddled. At JPET, we seem to change editorial contacts every six-to-nine months. It would be surprising if our publisher knew much about the journal or had any particular personal investment in it. With the Big Deal, JPET is often sold as part of a bundle. How can our publisher identify the value of one specific journal in this mix? What would be the positive effect of adding one more journal? Libraries can no longer signal that they want or do not want any specific offering. Thus, many potentially good new journals may not be founded, and many poor quality old journals may never be closed. There is increasingly little signal value in being published by a major press in this economic environment.

Thus, our experience at JPET has led us to this question regarding commercial publishers: What have you done for us lately? We think the answer has to be "Not much." The academy

4 Some publishers will post "accepted papers" unofficially on the journal's webpages. This is an improvement, but it is hard to understand why accepted papers are not placed officially in a journal once the page proofs are corrected except for the commercial convenience of the publisher. Scholars are hurt by this practice as it obscures the record of when an idea was produced and thus makes priority less clear.

5 Most commercial publishers offer libraries a "big deal" in which they get access to all of a publisher's titles in a given area in exchange for payments that are a fixed percentage higher than what they are currently paying a publisher for the individual journals to which they currently subscribe. These bundling deals usually are multi-year contracts with built in (and quite large) automatic cost increases. Such deals put the library in a position where it ultimately says yes or no to a publisher's entire portfolio in a research area and no longer makes individual acquisition decisions on a journal by journal basis. 
produces the research, edits and certifies the research, and ultimately consumes the research. It is hard to understand why we should continue to give the research away to commercial publishers and then buy it back at an enormous price. It is even more mysterious why we continue to tolerate the closed-access business models of commercial publishers. It results in interested colleagues being denied access to our research, which hurts both our intellectual mission and our personal professional advancement. ${ }^{6}$ In the papyrocentric era, publishers provided services essential to the distribution of new research. In the electronic era, commercial publishers only impede distribution and add insult to injury by charging huge fees for their trouble.

\section{Economics Bulletin and Open-Access Publishing}

All this theorizing may be very nice, but where is the proof that the academy can do things better and more cheaply? This question led us to put our beliefs to the test, founding a journal without a publisher.

In the year 2000, we circulated a proposal for a new journal called the Economics Bulletin (EB). This was meant to be a direct competitor with the Elsevier journal Economics Letters (EL). As the name suggests, EL's mission was to provide rapid and widespread dissemination of short notes, letters, and comments on current economic research. The problem, as we saw it, was that the publishers of EL were not accomplishing this mission. At the time, EL was largely paper-based, and library subscriptions cost on the order of $\$ 1500$. There was no such thing as a personal subscription price, and so the journal never came across the desks of individual researchers. It also took about eight months, on average, to get a paper published in EL. In large part, this lag was because of the paperbased editorial and publication system used by Elsevier.

In contrast, from the start, EB was designed to be open-access and completely electronic. The first thing we had to do was find a software platform. We searched, but everything we could find at the time was either too expensive or too limited. We decided that the best thing to do was to design our own system and hire a software engineer to write it. The fixed costs of writing the software were not trivial, but neither were they very great. The continuing costs of supporting the project have been relatively small, and of course, the marginal cost of allowing people access to the journal and its content are close to zero. We also have had help and support from many people and institutions. We would particularly like to thank Paula Kaufman of the UIUC library system, Zvi Ritz of the UIUC College of Commerce Office for Information Management, and Jody Combs and Dale Poulter of the Vanderbilt University library system.

6 There is some evidence that articles that are freely available have a greater research impact than those published in closed-access journals. See Antelman (2004), Eysenbach (2006), and Harnad et al. (2008), for example. 
The organizing principles of EB are the following:

- To provide open-access to all published content.

- To consider for publication notes, comments, and preliminary results, which must be seven pages or less excluding references, figures, tables, and appendices.

- To use the criteria that the paper be "correct, original, and of interest to a specialist" as the standard for publication.

- To consider submissions from all Journal of Economic Literature (JEL) subject categories.

- To publish also research announcements (a title and abstract of a paper and information about where a paper can be obtained), conference announcements, and letters to the editor. These are not refereed but are circulated via our email notification service and available on the Journal's webpage.

- To publish accepted papers immediately and without delay.

- To allow authors to retain full rights to use any content they publish at EB for any purposes they wish without constraint. Authors agree to grant EB a similar right to publish and distribute accepted content without constraint. (see http://economicsbulletin.vanderbilt.edu/Copyright.asp for details.)

- To use an editorial process that is decentralized in the sense that associate editors agree to handle specific JEL categories, choose referees, and make decisions about what to accept on their own authority.

- To try to make up-or-down decisions wherever possible and keep requests for revisions to a minimum.

The most remarkable thing about this experience is how the journal has grown. We have never done any formal advertising for the Economics Bulletin, but statistics for 2008 are as follows:

- $\quad$ EB will have received approximately 1000 new submissions in 2008.

- EB will have published approximately 350 papers (35\% acceptance rate) by the end of 2008.

- Average editorial turn-around time is about 33 days.

- EB gets about 5000 unique visitors per month directly at the site.

- EB gets an additional 6000 page views each month through RePEc.

- We have an automatic content notification service to which users can subscribe (for free). Approximately 5000 economists have signed up for this service.

- EB is archived by the University of Illinois at Urbana-Champaign and several other universities.

- EB allows free access to our full content through RePEc. 
- $\quad$ EB indexed by E-JEL.

EB can be seen at www.economicsbulletin.com.

The most important requirement for any journal to be successful-be it commercial or openaccess, paper or electronic-is that it serve a genuinely useful purpose. Finding an unserved niche is the first and most important thing to do. In the case of JPET, we were trying to create a focal point for a community of scholars in various areas of theory who wrote on public economics and also to foster communication between applied and theoretical researchers in the area. In the case of EB, two forces were at work. First, there was dissatisfaction with the way that EL was serving its mission and, especially, with the exploitative subscription prices that Elsevier charged libraries. Second, in 2000, a letters journal specifically aimed at publishing more minor results but rapidly using new electronic technology was much more likely to succeed than a new journal trying to publish more substantial pieces of research.

To elaborate a bit on the second point at that time, there was serious doubt about whether publishing in an electronic journal "counted" in the same way that publishing in a paper journal did. This was a legitimate concern, but we think it also missed the point. The problem with electronic journals in 2000 was not the medium in which they published but the fact that all electronic journals were new. All new journals are risky propositions and have unknown status. To the extent one is looking for creditable certification of one's research, one has to be cautious about sending one's work to a new publication. Letters, however, are a bit different than full-blown publications. They are meant to be short papers, subsidiary notes or comments. Thus, typically there is much less at stake in sending out such a manuscript to a less established publication. It is also the case that speedy publication is of more value for this kind of manuscript. Thus, a letters journal was in a relatively better position to compete with an established commercial offering than with a journal publishing full papers.

The evidence that the profession perceived that this was a niche that needed to be servedand also a major reason for EB's success-is the high quality of the editorial board. Remember that this is a working editorial board numbering about seventy-five, each of whom handles ten to thirty papers per year in his or her specific JEL categories. Establishing the board was a daunting task as we considered it in 2000. Many of the JEL categories were quite far from our own areas of research, and we did not personally know many candidates. It was important for the success of the journal that the editorial board be easily recognized as high quality. This need was especially true for an open-access, electronic journal without a commercial publisher as backer.

Here is the most remarkable thing about the whole experience of starting EB. We coldcalled people we had never met and explained what we were doing and why. About 85\% 
agreed to join the board simply because they believed in the mission of the Journal. For well-established researchers, membership on EB's board, at that time, was not likely to do anything for their careers and only meant taking on more work. If open-access is ever going to take over from commercial publishing, it will be on the back of this kind of publicspirited action by ranking members of the research community.

\section{AccessEcon, Workflow, and Content Management}

The experience at EB has led us to appreciate the power of the Internet as a workflow/content-management tool. The Economics Bulletin software was purposely written to run this one journal and has many elements hardwired. The possibilities for generalization are obvious, and we have been working on this since 2006 . The result can be viewed at www.accessecon.com.

Our objective in writing AccessEcon is to create a web-based application that allows the creation of electronic journals, working-paper series, and conferences organization interfaces. This is a turn-key system in which a new "publication" can be set up at will and then turned over to a webmaster, who customizes it to his or her needs and chooses editors, organizers, and other actors. We are also creating a "scholarly society" interface that allows the integration of these publications and allows for the maintenance of membership lists and so on. This is both a generalization and a specialization of the EB software. We have successfully tested the conference organization interface with PET07 and PET08, as well as the Social Choice and Welfare meetings in Montreal in 2008. The electronic journal software has been in use for JPET since the beginning of $2008 .^{7}$ In January of 2009 , we will capitalize on this success by retiring the original EB software and moving EB over to AccessEcon.

Running a journal efficiently is primarily a problem of workflow management. In general, workflow systems specify a set of rules that require objects (insurance claims or products that are manufactured, for example) to transit from state to state until they reach a terminal state. In the case of a journal, the objects are "manuscripts," and the state can be thought of as the current status in an editorial process. For example, when a paper is submitted, it transits to the first state, which we might call "new submission." When a manuscript is in this state, it is the responsibility of a specific actor; in this case, we will call him the "editor." The workflow rules allow the editor to send the manuscript out to other actors called "referees." Once the paper is sent out for review, it is in a state called "report requested," and when the referee undertakes a specific action, in this case "uploading a referee report," the paper goes to a state called "report received," and it is again the responsibility of the editor. The rules of the workflow system then allow the editor to move

7 We would like to thank attendees and organizers of these conferences and, especially, the editors, referees, and corresponding authors of JPET for their help in debugging and refining the software. 
the manuscript to one of several states: "decline," "accept," or "revision requested," for example. The first two are terminal states and can result in designated automatic actions taking place, such as an email declining a submission being sent to the authors and referees or the paper appearing in some designated format on the journal's web interface. The last is not a terminal state, and the responsibility returns to the corresponding author. The paper stays in this state until a revision is uploaded, and then the paper goes to state "revision received," at which point the editor becomes the responsible actor once more.

Obviously, workflow systems can be quite complicated. For example, the workflow rules might require that a certain number of referee reports arrive before a manuscript can go to a new status, or they might make all reports optional and allow the editor to short circuit the process at any point. All objects are not necessarily created equally or through the same procedure. It might be that "book reviews" skip the referee process but "articles" must get two referee reports. It also might be that similar objects get different treatment depending on other details in the metadata. At EB, for example, papers with different JEL categorization are automatically sent to different editors.

From the standpoint of efficient workflow, two things are important. First, an object can never get trapped in the system. There must always be a path to a terminal state. Second, any given object must always be the responsibility of at least one actor, and the system has a mechanism to make sure that the actor takes the actions required to move an object toward a terminal state.

In essence, an electronic workflow management system does most of what secretaries used to do in paper-based editorial systems. It keeps track of manuscripts, collects and files submissions and reports, sends out requests to edit and referee papers, reminds tardy editors and referees that actions are due, sends letters and reports to authors, and so on. The only thing left for editors to do in a well-conceived workflow system is to choose editors and referees, read papers and reports, and write decision letters; in other words, editors do only those things that require intellectual input and that would never be handed off to a secretary in any event.

If an electronic workflow-management system is a replacement for a secretary, then an electronic content-management system is largely analogous to a publisher. An electronic journal like EB publishes accepted content immediately by taking all the papers that are "accepted" and displaying them on the journal's web page in chronological order of acceptance. Alternatively, one might wish to publish in the more traditional form of periodically appearing issues and volumes. This change requires only adding a layer in which the editor is given the set of currently accepted papers and chooses from them to set up the current issue.

More generally, content management is a mechanism that allows a content provider (in this case a journal) to display content easily in some desirable format. There are thousands of 
ways to do so, of course. A good content-management system, therefore, needs to be designed to offer enough flexibility to be widely useful, but not be so general that the user has to wade through menus and options that are of little value. In other words, there is an essential balance between generality and usability. For this reason, the best contentmanagement systems are written with a community having a common set of needs in mind. For this reason, we have focused on the economics research community and not aimed to serve the broader academy with AccessEcon.

Notice that this kind electronic workflow/content-management system has direct application beyond the publishing of scholarly journals. For example, an editorial back-office is just an electronic journal without a content-publication system. A working-paper series is just an electronic journal that publishes accepted content immediately but which uses a "nonrefereed" editorial form. A conference organization interface is, first and foremost, a special case of an electronic journal. Papers are submitted (sometimes to special sessions/specific members of the organizing committee); some are accepted through a non-refereed editorial form and then put into sessions and made up into a program. Essentially, a program is just another version of a table of contents for an electronic journal.

Of course, we are glossing over some details. Search features; alternative ways of presenting content; subscribing to content notification systems; registering people for conferences; communicating with conference attendees; corresponding with authors, subscribers, and so on are other important features of a complete system. These generally fall outside of the standard workflow/content-management core, but are important usability features.

\section{Open-Access Business Models}

We have argued that, at this point in history, commercial publishers have very little to contribute to the process of scholarly communication. Indeed, they hinder it. So what keeps them in power?

The obvious answer is that good journals generally have a track record. That is, they are long established, which, in turn, means that they generally were founded in the papyrocentric era and thus are commercial journals (or society journals, which mostly follow the commercial business model, although more benignly as a rule). Scholars will tend to seek the most prestigious outlet for their work, so there is stability in the set of good journals. As new fields rise and old ones fall out of favor, there is opportunity to overturn this historical fact, but it will not happen overnight. Patience is required.

The bundling implied by the Big Deal is an attempt by commercial publishers to push the day that they collapse off into the future. It makes it harder for libraries to signal their 
dissatisfaction with any specific journal. Libraries who have agreed to a big deal cannot readily drop a title when an open-access or cheaper society offering overtakes a commercial offering in value. Thus, instead of dying a slow death with weak journals being picked off and replaced by new ones outside of the commercial offering, commercial offerings lend each other mutual support. Dropping out of a Big Deal, of course, is a big deal for libraries. The merging of commercial publishing giants that we have seen in recent years serves to up the ante further by making the bundle that much bigger and harder to drop.

Bundling is clever strategy that allows publishers to take advantage of uncertainty in underlying demand. Different universities will have different concentrations of specialists in different fields. These concentrations will change over time. Different groups of researchers also will level influence to affect subscription choices that vary over time. Often, it will turn out that a given journal will not be worth the cost to a university and would have been dropped in the pre-Big Deal days. Over time, with new offerings becoming available and library budgets under increasing stress, it would have been increasingly difficult to get those subscriptions picked up again. With an "all or nothing" Big Deal offer, at any given time, journals that happen to be more strongly valued will carry the weaker ones. Random shifts in faculty interest will be balanced out, and the overall bundle will still be worth the cost. This argument largely derives from Bergstrom and Bergstrom (2001).

On the other hand, in our opinion, there have been some missteps on the open-access side that we think have led to poor business models. Academics often hear about the need to get grant support or to charge large publication or submission fees. The basic idea is that it is somehow very expensive to publish a journal. We argue this is a misconception. ${ }^{8}$

As we mentioned above, it seems to us that by far the greatest part of spending by commercial publishers is related to advertising for subscriptions, fulfilling subscriptions, and policing access to content, as well as managing all this, paying taxes, employing lawyers and accountants, and so on. None of this activity is closely related to facilitating scholarly communication.

We conclude that commercial participation in scholarly communication is a bit like feeding bread to birds in the park. In the papyrocentric era, publishers were the only food source available to journals. Journals, including members of editorial boards and authors, had to go to them or starve. The fact that publishers made a living off the birds might have been resented, but there was little to be done. In the electronic era, food is abundant. Birds tend to resent being exploited, so one wonders why journals continue to stay with commercial publishers. Some birds are too old to change. Other birds have been captured and cannot escape. As these birds grow old, however, it will be difficult for publishers to replace them. With food as easily available as it is in the electronic era, it would have to be a pretty dim

8 See for example Getz (2004) and Graczyński and Moses (2004) who report on concerns that open-access journals do not have much cost advantage over commercial journals. 
pigeon indeed who would decide to strike the same bargain with commercial publishers as did his fore-bearers. There simply is no need in the new environment.

So what really are the required expenses for running an open-access journal?

- Printing and binding? Not required. This is from a bygone era. (Of course, a journal might also choose to publish paper volumes, available for purchase for the benefit of conservative libraries and for those who like to see their work in print).

- Typesetting? A luxury, but one that can be had at the cost of a couple of hundred dollars per paper (or less) if desired.

- Advertising? The best advertising is through word of mouth by reputable scholars in an area. This comes automatically if the editorial board is a good one and can be helped with such things as self-funded conferences; Google Scholar and RePEc are also very good sources for advertising for open-access content. Remember openaccess journals are not trying to sell subscriptions, only to persuade people to submit papers and read the content.

- Secretarial help? Not required if you have a good workflow and contentmanagement system. EB has never used any secretarial help, and since 2008, when JPET moved to the new AccessEcon interface, there has been no role for secretarial help.

- Postage? This is only required if paper needs to change hands. With electronic journals, everything is handled by email and Internet interfaces.

- Editorial salaries? While these are certainly very nice, we believe that they are not required. The main rewards to being an editor are personal (helping to support intellectual activities that one cares about) and professional (status, raises, etc.). There will never be a shortage of editors for good journals that contribute to the intellectual life of the academy. ${ }^{9}$

- Referee stipends? Not required. It is not clear that there is a stipend for which an otherwise uninterested referee will write a good report.

- Writing workflow/content-management software? This can be expensive, but it is a one-time expense. There are now fairly cheap and even open-source tools available for this. More will be said on this below.

- Software and hardware maintenance? Problems will always arise: servers go down, processes get hung, systems are incompatible. Hosting one's own software on a dedicated server can cost a couple thousand dollars per year, but this can be less or even zero if you get help from a university or share hosting. Depending on local expertise and support, these maintenance expenses can range from nothing to three or four thousand per year altogether. Note also there is an obvious economy of scale here when many journals share the same hosting and software.

9 Most of the cost of writing the EB and AccessEcon software was paid for out of our JPET editorial salaries. Perhaps this is one good use for such expenses. 
Putting this information together, there are two major categories of expenses for running an open-access electronic journal. First, there is the fixed cost of finding, buying, renting, or developing workflow/content-management software. Second, there are costs ranging from close to nothing to a few thousand dollars per year to run and maintain the software and website.

Thus, it is a myth that a journal must collect tens of thousands of dollars to pay current costs. (We will consider software development costs later.) Submission fees in the hundreds of dollars and, especially, publication fees in the thousands of dollars are hard to justify. They only create rents that are wasted by commercial publishers or used to offset overhead expenses that are either inessential to publishing the journal or that fund other (possibly worthy) spending by scholarly societies. In light of this information, for anyone with an interest in scholarly communication, it is especially hard to justify subscription fees. Such fees are antithetical to the mission of scholarly commutation; tend to create intellectual inequalities in which people at better institutions have better access than those at more modest institutions; and do not serve the intellectual or professional interests of the scholars contributing the content.

Publication fees, in particular, are worrisome because they create a potential for a conflict of interest. Paying for publication leads to a temptation to publish a paper regardless of quality. Such fees are a hold-over from a time when each page published had to reproduced and mailed to the entire subscriber base of a journal. Publication fees in the papyrocentric era could, therefore, be viewed as offsetting this incremental cost to a journal, and thus, could in fact reverse a distortionary financial incentive not to publish a paper. . Of course, in the electronic era this problem is gone, and there are virtually zero marginal costs to publishing a paper, regardless of the number of pages.

In contrast, there is a positive case to be made for submission fees in the electronic era. Submitting a paper for review requires that effort be spent by editors and referees. Submission fees encourage the author to at least partially internalize these costs. One has to balance this positive effect with the negative effects on authors (especially graduate students and those from developing countries) and the fact that new journals might want, at first, to encourage all the submissions it can get. However, submission fees should not be seen as distortionary and, fortunately, would be quite sufficient to cover the modest annual costs of supporting a journal.

Let us return to the cost of electronic workflow/content-management systems. There are a number of existing alternatives. Editorial Express (www.editorialexpress.com) offers workflow and some content management for about $\$ 2000$ per year. Connected with this site is a conference organization interface, Conference Maker (http://editorialexpress.com/conference/), for which the per use fee is not clear. One attractive feature of this system is that it is purposely written for economics and related social sciences, thus avoiding a lot of generality that would only clutter the system and not 
be valued by the user community. In addition, Editorial Manager (http://www.editorialmanager.com/) has a model similar to Editorial Express. Journals are hosted by the company on company servers. The costs are not clear, but the site suggests that the costs of Editorial Manager are quite a bit higher than those of Editorial Express. The system looks quite customizable, but it is not written with economists in mind. Thus, there are many features that add clutter without value.

Open Journal Systems from the public knowledge project (http://pkp.sfu.ca/ ?q=ojs) takes a somewhat different approach. This is open-source software that you install and maintain on your local machine. Thus, there is a loss of the economy of scale in support and hosting, and it requires more local expertise. On the upside, it is free. On the downside, it has many features that are not of value to economists, and reports we have heard from people working with it suggest it is a rather cumbersome system.

BE Press (http://www.bepress.com/) hosts journals, but it is essentially a standard commercial publisher offering only electronic content. It charges both submission fees and subscription fees. A typical journal costs libraries $\$ 300-\$ 500$, and the entire bundle of 42 journals costs about $\$ 8000$. To give BE Press credit, its journals are cheaper than typical commercial publisher prices, and it does offer clear a la carte pricing. Whether to class it as open or closed access is an interesting question. If your university does not subscribe, you can get access to an individual PDF at the cost of filling out a form that recommends the journal to your library. There does not seem to be commitment to maintaining even this limited form of open-access, however.

Social Science Research Network (http://www.ssrn.com/) hosts journals, working papers, and working-paper services. It charges institutions and individuals for full access but also has much content available for free. SSRN hosts working papers series for departments and institutions for about $\$ 7000$ per year plus some incremental costs.

Theoretical Economics (http://econtheory.org/) is an example of a true open-access journal. It uses its own purpose-written content-management and workflow software. Submission fees are a reasonable $\$ 75$, and there is a page charge for publication, ranging between $\$ 0$ and $\$ 10$. This charge is to offset the cost of typesetting and reflects the marginal costs the journal pays for these services. Whether or not $\$ 200$ to $\$ 300$ per article might discourage some people from wanting to publish in a start-up journal and whether typesetting is worth this risk is debatable. In any event, these fees certainly cannot be called exploitative or distortionary. Most importantly, TE is strictly open-access.

We have a different business model at AccessEcon. Our experience with JPET, EB and APET, especially its conferences, has lead us to the conclusion that editors, conference organizers, working paper series coordinators, and other facilitators of scholarly communication still have difficulty finding workflow and content management tools that make it possible to provide their services. Since we argue that the cost of workflow content 
management are the only remaining items that content providers have difficulty producing themselves (and which still cost money), this is the key bottleneck. Thus, our objective is to make a flexible tool available to the economics research community to facilitate open-access scholarly communication. Specifically, Accessecon will offer the following:

- Hosting of open-access economic journals. AccessEcon software provides both a flexible workflow-management system and content-publication system. The system will allow for the collection of submission fees but not provide any digital rights management system. The system is open-access by design. Starting or running a journal takes both a commitment and a well-conceived mission. Because it is not our wish to add to the growing flood of useless information, we will exercise judgment about whether to host any given journal. However, there is no fee for hosting openaccess journals. Given that we will host and support the software, this means that the cost of running an open-access journal at AccessEcon is zero. All that is required is the intellectual work of editing and refereeing.

- AccessEcon also will host submission interfaces (but not content-publication service) for non-open-access journals for a small fee. Editors can use the system to manage content and put together tables of contents and collections of accepted papers to send to publishers, but will not be able to publish with the system unless they are willing to allow open-access to the content.

- Conference organization interface: AccessEcon has a complete conference organization package that does everything from managing submissions, to putting together a program, to handling registration. This interface will be made available free of charge to any group organizing conferences in economics. The only requirement is that current conference organizers agree to answer occasional questions from future conference organizers new to the system. This kind of "mutual support" makes scaling up usage feasible, and helping one's colleagues in this way should not impose an unreasonable burden.

- Working-paper series: AccessEcon will host working-paper series for any economics department, research group, or society free of charge, subject only to the same mutual support requirement given for conferences.

- Association websites: AccessEcon will host scholarly society website interfaces for any economics group, subject only to the mutual support agreement. This interface will integrate conferences, working papers, and publications of societies hosted at AccessEcon and will also help societies manage their membership lists.

- Personal research pages: Any economist can set up a personal research page at AccessEcon free of charge. This service will begin in mid-2009. 
Thus, our business model is to offer almost all of these services for free. A good question is: Why is this a sensible business model? There are several reasons. First, the reason that we wrote this software to begin with was to support JPET, APET, and EB. Thus, we would have encountered this fixed cost in any event. There are very few additional fixed costs to recover. Second, the marginal cost of allowing others to use the system is very close to zero. We are good enough public economists to know that the efficient price is zero in this case. The only marginal costs to us are the time it takes to get others started on the system. This is the reason for the "mutual support" condition. Third, after careful reflection, we realized that we simply are not business people. The cost in terms of time away from research of shilling, billing and advertising isjust not worth the potential financial benefit. To mangle the old joke about arbitrage: if there are five dollar bills lying on the ground then it must be because it costs ten dollars to pick them up. To put it another way, we have learned a lesson from commercial publishers (even some of the new electronic commercial publishers mentioned above) and do not intend to become yet another snake eating its own tail. Finally, because of our experience at JPET and EB, we sincerely want open-access to spread as widely and rapidly as possible, especially in economics. To nickel and dime people who share this vision seems completely self-defeating.

\section{Conclusion}

Our conclusion is that, in the electronic era, open-access electronic journals have an overwhelming cost advantage over commercial publishers. In addition, open-access is consistent with our mission as scholars to increase and spread knowledge and also feeds our personal and professional interests much more directly. However, we are still largely living with the system of scholarly communication we inherited from the papyrocentric era. This system will not go quietly into the night. Commercial publishers will do their best to hang on to and exploit this inherited capital as long as they can.

As individual scholars, we will continue to act in our own self-interest and so will try to place our research in the most reputable journal we can. Whether this location is an openaccess journal, a cheaper society journal, or an expensive commercial journal will play little role in this decision. There is no reason to complain about this, and very little that can be done to change it.

What we can do is undertake the hard work of creating credible open-access alternatives. Creating such alternatives means finding areas that are not well served by the current set of commercial journals, enlisting the support of leaders in these research areas, and then building communities around these new journals. The incentives are there for 
entrepreneurial editors to do so. With AccessEcon and other electronic workflow/contentmanagement tools available, the financial barriers to entry are close to zero.

\section{References}

Antelman, K. (2004) "Do Open Access Articles Have a Greater Research Impact?" Working paper. http://eprints.rclis.org/2309/.

Bergstrom, C., and T. Bergstrom (2001) "Do University Site Licenses for Academic Journals Benefit the Scientific Community?" Working paper Department of Economics, UCSB. http://works.bepress.com/ted bergstrom/22/.

Bergstrom, T. (2001) "Free Labor for Costly Journals.” Journal of Economic

Perspectives, 15: 183-98.

Boldrin, M., and D. Levine (2008) Against Intellectual Monopoly, Cambridge University Press.

Eysenbach, G. (2006) "Citation Advantage of Open Access Articles" PLoS Biology 4(5): e157.

Getz, M. (2004) "Open-Access Scholarly Publishing" Journal of Library Administration 42(1): 1-39.

Graczyński, M., and L. Moses (2004) "Open Access Publishing-Panacea or Trojan Horse?" Medical Science Monitor 10(1): ED1-3.

Harnad, S. (1994) Scholarly Journals at the Crossroads: A Subversive Proposal for Electronic Publishing Edited by Edited by Ann Shumelda Okerson and James J. O'Donnell, Available at: http://www.arl.org/sc/subversive/

Harnad, S. ,T. Brody, F. Vallières, L. Carr, S. Hitchcock, Y. Gingras, C. Oppenheim, C. Hajjem, and E. Hilf (2008) "The Access/Impact Problem and the Green and Gold Roads to Open Access: An Update" Serials Review, 34(1): 36-40.

Willinsky, J. (2005) "Scholarly Associations and the Economic Viability of Open Access Publishing" Open Journal System Demonstration Journal, 1(1). 